\title{
Relationship between the dark triad and depressive symptoms
}

\author{
Raquel Gómez-Leal ${ }^{1}$, Alberto Megías-Robles ${ }^{\text {Corresp., } 1}{ }^{1}$, María José Gutierrez-Cobo ${ }^{2}$, Rosario Cabello ${ }^{2}$, Enrique G \\ Fernández-Abascal ${ }^{3}$, Pablo Fernández-Berrocal ${ }^{1}$ \\ 1 Department of Basic Psychology, University of Málaga, Málaga, Spain \\ 2 Department of Developmental and Educational Psychology, University of Granada, Granada, Spain \\ 3 Faculty of Psychology, Universidad Nacional de Educación a Distancia, Madrid, Spain \\ Corresponding Author: Alberto Megías-Robles \\ Email address: amegias@uma.es
}

The Dark Triad (DT) is composed of three closely related personality traits: psychopathy, Machiavellianism, and narcissism. These traits have been linked to emotional deficits. The aim of the present study was to analyse the relationship between the DT traits, including sub-dimensions, and depressive symptoms in order to identify those factors most strongly associated with the development of depression in individuals scoring high on DT. For these purposes, a total of seven hundred and ninety-one adults ( $M=35.76$ years; $24.91 \%$ males) completed a questionnaire battery including DT traits and depression measures. A positive significant correlation was found between psychopathy and Machiavellianism traits (total score and all sub-dimensions) and depressive symptoms. For narcissism, the direction of the correlation was dependent on the sub-dimension assessed. A model explaining $26.2 \%$ of the depressive symptoms scores was composed of the callous affect and criminal tendencies sub-dimensions of psychopathy, cynical view of human nature, which is a sub-dimension of Machiavellianism, and entitlement and self-sufficiency, which are sub-dimensions of narcissism. In addition, some of the relationships found between DT sub-dimensions and depressive symptoms appeared to depend on gender. Our results could have implications for detection and intervention programs aimed at decreasing the negative emotional consequences suffered by individuals with high DT scores. Limitations and future lines of research are discussed. 
1

2

\title{
Relationship between the dark triad and depressive symptoms.
}

\section{Raquel Gómez-Leal ${ }^{1}$, Alberto Megías-Robles ${ }^{1 *}$, María José Gutiérrez-Cobo² ${ }^{2}$ Rosario} Cabello $^{2}$, Enrique G. Fernández-Abascal ${ }^{3}$, and Pablo Fernández-Berrocal ${ }^{1}$

\author{
1 Department of Basic Psychology, University of Málaga, Málaga, Spain \\ 2 Department of Developmental and Educational Psychology, University of Granada, Granada, \\ Spain \\ 3 Faculty of Psychology, Universidad Nacional de Educación a Distancia, Madrid, Spain
}

*Corresponding author

Alberto Megías Robles

7 University of Málaga

8 Faculty of Psychology, Department of Basic Psychology.

29 Campus Teatinos, s/n. 29071. Málaga, Spain

30 Email: amegias@uma.es 


\section{Abstract}

The Dark Triad (DT) is composed of three closely related personality traits: psychopathy, Machiavellianism, and narcissism. These traits have been linked to emotional deficits. The aim of the present study was to analyse the relationship between the DT traits, including sub-dimensions, and depressive symptoms in order to identify those factors most strongly associated with the development of depression in individuals scoring high on DT. For these purposes, a total of seven hundred and ninety-one adults $(\mathrm{M}=35.76$ years; $24.91 \%$ males $)$ completed a questionnaire battery including DT traits and depression measures. A positive significant correlation was found between psychopathy and Machiavellianism traits (total score and all sub-dimensions) and depressive symptoms. For narcissism, the direction of the correlation was dependent on the sub-dimension assessed. A model explaining $26.2 \%$ of the depressive symptoms scores was composed of the callous affect and criminal tendencies sub-dimensions of psychopathy, cynical view of human nature, which is a sub-dimension of Machiavellianism, and entitlement and self-sufficiency, which are sub-dimensions of narcissism. In addition, some of the relationships found between DT subdimensions and depressive symptoms appeared to depend on gender. Our results could have implications for detection and intervention programs aimed at decreasing the negative emotional consequences suffered by individuals with high DT scores. Limitations and future lines of research are discussed. 


\section{Introduction}

63

The term Dark Triad (DT) describes a set of three distinct but related sub-clinical personality traits: psychopathy, Machiavellianism, and narcissism (Paulhus \& Williams, 2002). These traits have often been associated with negative aspects of personality; for instance, psychopathy is related to higher levels of aggressiveness and impulsivity (Kennealy, Skeem, Walters, \& Camp, 2010), Machiavellianism is linked to hypocrisy and manipulation (Paulhus \& Williams, 2002), and narcissism is linked to dominance, superiority, and egocentric attitude (Paulhus \& Williams, 2002). Among these undesirable outcomes we can also find emotional deficits such as anxiety or low empathy associated with the three DT traits (Megías, Gómez-Leal, Gutiérrez-Cobo, Cabello, \& Fernández-Berrocal, 2018; Miller et al., 2010; Jonason \& Kroll, 2015), as well as difficulty in regulating mood and alexithymia associated with psychopathy and Machiavellianism (Miao, Humphrey, Qian, \& Pollack, 2018; Cairncross, Veselka, Schermer, \& Vernon, 2013). The aim of the current study was to explore how the three personality traits comprising the DT could be related to depressive symptoms.

Depression is one of the most common mental disorders worldwide (Lépine \& Briley, 2011). This disorder is considered a major public health problem because of the consequences it entails, not only for those affected and their family members but also for society, with very high economic costs in terms of the use of services and loss of productivity (Cassano \& Fava, 2002). The most common depressive symptoms are continuous depressed mood, and somatic and cognitive changes that affect the individual on a day-to-day basis such as a general loss of interest, low self-esteem, irritability, or changes in appetite and sleep (American Psychiatric Association, 2013). Moreover, research has revealed that women, in comparison with men, show a higher prevalence, incidence, and morbidity risk of depressive symptoms, beginning at mid-puberty and persisting through adult life (Piccinelli \& Wilkinson, 2000).

Psychopathy, Machiavellianism, and narcissism are all encompassed by the DT construct because they share a common core of important characteristics such as callous-manipulation, tendencies towards self-promotion, and the performance of norm-violating acts, deception, and 
89

90

91

92

93

94

95

96

97

aggressiveness (Furnham, Richards, \& Paulhus, 2013; Paulhus \& Williams, 2002). However, despite the overlap between these traits, each has their own unique particularities and is composed of different sub-dimensions. Psychopathy is characterized by thrill-seeking behaviours, dishonesty, egocentricity, manipulation, and antisocial behaviour (Hare, 1993); Machiavellianism is characterized by exploitative behaviour, insincerity, and callousness (Christie \& Geis, 1970); and narcissism is characterized by exhibitionism, feelings of superiority, dominance, and admiration seeking (Morf \& Rhodewalt, 2001; Raskin \& Terry, 1988).

Recent years have seen an exponential rise in the level of attention paid to studying DT (Watts, Waldman, Smith, Poore, \& Lilienfeld, 2017; Muris, Merckelbach, Otgaar, \& Meijer, 2017). Although there is a specific literature showing the advantages of scoring high on DT traits, such as greater confidence, commitment, control, and physical activity (Sabouri et al., 2016a; Sabouri, et al., 2016b), much of the research on DT has focused on the negative consequences that these traits may have for society in general (e.g., Kennealy et al., 2010). However, relatively little importance has been assigned to the negative emotional consequences that may be suffered by individuals scoring high on the DT. We believe it is important to consider not only those outcomes that affect society, but also the personal consequences that may affect individuals with high DT scores, such as depressive symptoms. In this regard, a number of previous studies have explored the relationship between depression and some of the three DT personality traits separately (e.g., Al Aïn, Carré, Fantini-Hauwel, Baudouin, \& Besche-Richard, 2013; Stinson, Becker, \& Tromp, 2005), but, in order to provide a better understanding of this relationship, it is necessary to characterize the DT term that encompasses a concurrent analysis of the three personality traits and their sub-dimensions (Jones \& Paulhus, 2017).

Research analysing the relationship between depressive symptoms and psychopathy have yielded mixed results. Whilst some studies have found a negative relationship between depression and psychopathy (Stalenhei \& Von Knorring, 1996), others have found a positive relationship between these constructs (Stinson et al., 2005; Tokarev, Phillips, Hughes, \& Irwing, 2017). For instance, Stinson et al. (2005) observed that depressive symptoms are common in extreme psychopathic groups. Second, in relation to Machiavellianism, although there are also some conflicting findings, these tend to be more consistent in showing a positive relationship between both concepts. For example, Al Aïn et al. (2013) found a positive correlation between the total score on the Machiavellianism IV Scale (Christie \& Geis, 1970) and the total score on the Beck 
120 Depression Inventory II (Beck, Steer, \& Brown, 1996). Finally, research focused on narcissism

121 has shown that there appears to be no relationship between this trait and depression (e.g. Jonason,

122 Baughman, Carter, \& Parker, 2015). This could be due to the fact that narcissism - although

123 associated with maladaptive behaviour — is also related to subjective wellbeing (Rose \&

124 Campbell, 2004). To our knowledge, only one study has explored the relationship between the

125 three DT traits and depression (Jonason et al., 2015). In this study, Jonason et al. (2015) found a

126 positive relationship between depression and the traits of psychopathy and Machiavellianism.

127 However, this study did not consider the different sub-dimensions of the DT traits and it is focused

128 on general measures of wellbeing. Given that each sub-dimension is related to different

129 characteristics, it is important to analyse each of these separately in order to draw more specific

130 conclusions and to fully understand the possible clinical and social implications of the findings.

131 For this reason, in the present study we focused on all the sub-dimensions of the DT traits.

132

133

In addition, previous research has revealed gender differences in the personality traits comprising the DT. Firstly, in relation to psychopathy, both in clinical and community samples, this trait has shown to be much stronger in men than in women (e.g., Cale \& Lilienfeld, 2002, Nicholls, Ogloff, Brink, \& Spidel, 2005). Secondly, although there are few studies analysing the relationship between Machiavellianism and gender, these have also shown higher scores for men than women (e.g., Krampen, Effertz, Jostock, \& Müller, 1990). Finally, through a meta-analysis in which 355 studies were included, Grijalva et al. (2015) found that men scored higher than women on narcissism. All of these previous findings emphasize the importance of incorporating gender differences in the study of DT traits.

A more detailed analysis of the relationship between depressive symptoms and the subdimensions of the DT traits that considers gender effects could help professionals and researchers to establish better emotion-oriented treatments in people with high scores on DT traits. This issue is of importance because the comorbidity of high scores on DT traits and depression could prolong the time needed to respond to depression treatment (Mulder, Joyce, \& Luty, 2003), lead to a higher frequency of relapses (Ramklint \& Ekseliusand, 2003) or even result in extreme cases such as ideas (Nock, Hwang, Sampson, \& Kessler, 2010). 
The main objective of this study was to analyse the relationship between the personality 150 traits associated with DT and the possibility of presenting depressive symptoms. To carry out a 151 detailed study of this relationship, we focused on each of the sub-dimensions of each DT trait in 152 an attempt to develop a model that helps to identify those DT factors that are most strongly 153 associated with depressive symptoms. In addition, given the previously demonstrated gender 154 differences in DT traits, we also examined whether the relationship between these traits and the 155 sub-dimensions of depression are equal across genders. We hypothesize that (1) there are gender 156 differences in the total scores and sub-dimensions of the DT traits; (2) there is a positive 157 relationship between depressive symptoms and the psychopathy and Machiavellianism traits; (3) 158 there is no significant relationship between depressive symptoms and narcissism; (4) the 159 relationships between depressive symptoms and DT traits are moderated by gender; and (5) 160 depressive symptoms could partially be related to the joint effect of a set of sub-dimensions of the 161 DT traits.

162

163

\section{Method}

164

Participants

Seven hundred and ninety-one volunteer participants from the Spanish National Distance Education University took part in this study. The age of the sample ranged from 18 to 66 years, with a mean of 35.76 years $(\mathrm{SD}=9.54)$. One hundred and ninety-seven of the participants were 168 men (24.91\%). All participants were informed that confidentiality and anonymity of the collected data would be assured, and all were treated in accordance with the Helsinki declaration (World Medical Association, 2008). The Research Ethics Committee of the University of Málaga approved the study protocol as part of the project SEJ-07325 (IRB approval number 10-2018-H).

Procedure and Instruments

Participants completed the depression and DT questionnaires online through LimeSurvey platform (http://limesurvey.org). They needed approximately 30 minutes to complete the whole study. Access to the questionnaires was provided via email invitation from the authors. Informed

176 consent was found on the first page of the online questionnaire, where they were assured of the 177 confidentiality of their responses. The questionnaires were set up so that empty responses were not 
178 allowed in order to avoid the possibility of missing data. A description of each scale is detailed 179 below:

Beck Depression Inventory II (BDI-II; Beck et al., 1996). The BDI is a 21-item self-report

181

182

183

184

185

186

187

188

189

190

191

192

193

194

195

196

197

198

199

200

201

202

203

204

205

206

207

The 34-item Self-Report Psychopathy Scale-III (SRP-III; Mahmut, Menictas, Stevenson, \& Homewood, 2011). The SRP-III is a 34-item self-report measure of psychopathic traits based on a four-factor structure model of psychopathy (Hare \& Neumann, 2005; Vitacco, Neumann, \& Jackson, 2005). The questionnaire includes a total score and four sub-dimension scores: interpersonal manipulation (IPM), criminal tendencies (CT), erratic lifestyle (ELS), and callous affect (CA). Responses are given on a 5-point Likert type scale ranging from 1 ("Disagree strongly") to 5 ("Agree strongly"). The Spanish version of the questionnaire was used in our study (Gómez-Leal et al., 2019). Internal consistency for the sample of the present study was good (ordinal omega of the total score was 0.92 , whilst for the sub-dimensions this ranged between 0.77 and 0.89$)$.

Machiavellianism-IV Scale (MACH-IV; Christie \& Geis, 1970). The Mach-IV is a 20-item self-report measure. Ten items are related to high Machiavellianism and 10 items to low Machiavellianism. Participants are requested to rate the extent to which they agreed or disagreed with the statement of each item using a 6-point Likert scale ranging from 1 ("Strongly Disagree") to 6 ("Strongly Agree”). Mach-IV contains a total score and three sub-dimensions: interpersonal tactics (T), cynical view of human nature (V), and disregard for conventional morality (M). One of the items in the M sub-dimension was removed because it is outdated, according to suggestions 
208 in the previous literature (e.g., Rauthmann, 2013). We used the Spanish version of the

209 questionnaire (Rada, de Lucas Taracena, \& Rodríguez, 2004). Internal consistency for the sample

210 of the present study was adequate (ordinal omega of the total score was 0.79 ; whilst for the sub-

211 dimensions this ranged between 0.70 and 0.72 ).

212 Narcissistic Personality Inventory (NPI; Raskin \& Hall, 1979; Raskin \& Terry, 1988). The

213 NPI consists of 40 forced-choice items, where the participants must choose between two

214 alternative statements, scoring 1 point if they choose the narcissistic statement and 0 points if they

215 choose the non-narcissistic statement. NPI includes a total score and seven sub-dimensions:

216 authority (AUT), self-sufficiency (SS), vanity (VAN), exploitativeness (EXP), superiority (SUP),

217 exhibitionism (EXH), and entitlement (ENT). We used the Spanish version of the questionnaire

218 (García \& Cortés, 1998). Internal consistency for the sample of the present study was adequate

219 (ordinal omega of the total score was 0.87, whilst for the sub-dimensions this ranged between 0.67

220 and 0.81$)$.

221

222

Data analysis

223

224

225

226

227

228

229

230

231

232

233

234

235

236

237

In order to study the relationship between the DT and depression, we conducted the following analyses. First, descriptive statistics were carried out to explore the characteristics of the total scores and all the sub-dimensions of the measures employed. Moreover, possible gender differences for each variable were explored using Mann-Whitney U tests. Second, the relationship between depression and DT was evaluated using Spearman's correlation analysis, both for the whole sample (men and women) and divided according to gender. Mann-Whitney $U$ tests and Spearman's correlations were used given that the normality assumption was rejected for the variables included in the study (Kolmogorov-Smirnov test $<.05)$. Third, we explored possible gender differences in the significant correlations found in the previous step using Fisher's Z-test. Descriptive statistics, Mann-Whitney U tests, Spearman's correlations, and Fisher's Z-test were conducted using the SPSS ${ }^{\circledR}$ version 23.0 (IBM Corporation, Armonk NY, USA) and FZT computator (http://psych.unl.edu/psycrs/statpage/regression.html). The alpha level was set at 0.05 for all the analyses.

Finally, we carried out a generalized additive model (GAM; Hastie \& Tibshirani, 1990; Wood, 2017) in order to identify the sub-dimensions of the DT traits most strongly associated with 
238 depression. The GAM allows for modelling complex relationships between variables through both

239 linear and non-linear, parametric and non-parametric smoothing functions combined in the same 240 model. This semi-parametric approach was used, since normality and homoscedasticity 241 assumptions were rejected. The values of the residuals were not normally distributed (Shapiro242 Wilks test: $p<.05$ ) and their variance was not constant (checked by visual inspection of the scatter 243 plot showing the standardized residuals against the standardized predicted values). The 244 multicollinearity assumption was not violated (always VIF $\leq 1.79$ and tolerance $\geq .65$ ). We 245 introduced into the model those DT sub-dimensions that were significant for the whole sample in 246 the correlational analysis. Each of these sub-dimensions was included as a smooth term. The main 247 effect of gender was introduced as a predictor to control for the possible influence of this variable.

248 Total scores were not included, given that these are the result of averaging their sub-dimensions.

249 The basis dimension used to represent the smooth terms was determined automatically using 250 penalized regression splines by the mgcv package (Wood, 2017). The GAM analysis was 251 conducted using the statistical software R 3.6.1. (R Core Development Team 2019) with the mgcv 252 package (Wood, 2017). The alpha level was set at 0.05.

253

\section{Results}

Table 1 shows the descriptive statistics and gender differences for the variables included in the study (total scores and sub-dimensions). We observed that men, in comparison with women, showed higher levels of psychopathy on the total score and all its sub-dimensions (except in the callous affect sub-dimension), higher levels of Machiavellianism on the total score and the interpersonal tactics and disregard for conventional morality sub-dimensions, and higher levels of narcissism on the vanity and entitlement sub-dimensions.

- Insert Table 1 -

262

263

Spearman's correlation analysis conducted for DT and depressive symptoms for the whole 264 sample (men and women) revealed that the higher the psychopathy and Machiavellianism scores 265 (total score and all sub-dimensions), the higher the depressive symptoms. In the case of narcissism, 266 higher scores on the self-sufficiency sub-dimension were related to fewer depressive symptoms, whilst higher scores on the entitlement sub-dimension were related to more depressive symptoms. 
268 When the sample was divided by gender, a similar pattern of results was found, with the exception 269 that men showed a positive relationship between the exhibitionism sub-dimension of narcissism 270 and depressive symptoms, and women showed a negative relationship between the vanity and 271 superiority sub-dimensions of narcissism with depressive symptoms. In addition, women did not 272 show a relationship between the disregard for conventional morality sub-dimension of 273 Machiavellisanism and depressive symptoms (see Table 2). When specific gender comparisons 274 were made with respect to the correlations using the Fisher's z-test, it was found that women, 275 compared with men, showed a stronger negative relationship between the narcissism sub276 dimensions of self-sufficiency $(Z=2.06, p<.05)$ and vanity $(Z=2.31, p<.05)$ with depressive 277 symptoms. Moreover, men, compared with women, showed a stronger positive relationship 278 between the Machiavellianism sub-dimension of disregard for conventional morality $(\mathrm{Z}=2.10, p$ $279<.05)$ and depressive symptoms.

280

Finally, the GAM analysis revealed five significant sub-dimensions, which explained $26.3 \%$ of the total variance. The significant sub-dimensions were criminal tendencies (estimated $d f=6.95, F=5.31, p<0.001$ ) and callous affect (estimated $d f=1.00, F=10.83, p=0.001$ ) from psychopathy, cynical view of human nature (estimated $d f=1.86, F=7.28, p<0.001$ ) from Machiavellianism, and self-sufficiency (estimated $d f=2.75, F=19.83, p<0.001$ ) and entitlement (estimated $d f=1.00, F=4.57, p=0.03$ ) from narcissism. Figure 1 presents the shape of the significant relationships. According to the estimated degree of freedom $(1 \mathrm{df}$ corresponds to a linear fit) and graphic representation, the relationships between depressive symptoms and the callous affect and entitlement sub-dimensions were linear and showed a positive association. The relationships between depressive symptoms and each of the sub-dimensions of criminal tendencies, cynical view of human nature, and self-sufficiency were all non-linear (df larger than 1). However, despite the non-linear relationship, both criminal tendencies and cynical view of human nature also showed a general tendency to increase along with the increase in depressive 296 symptom scores, particularly for the highest scores on criminal tendencies. With respect to self- 
297 sufficiency, a negative relationship was observed with depressive symptoms, except for the highest

298 scores on self-sufficiency.

299

300

- Insert Figure 1 -

301

302

4. Discussion

303

304

305

306

307

308

309

310

311

312

comparison with women are compatible with scientific evidence showing that in general men

313 present more antisocial behaviours due to social or genetic factors (Cale \& Lilienfeld, 2002; Book, Starzyk, \& Quinsey 2001; Reidy, Shirk, Sloan, \& Zeichner, 2009). The higher scores that men showed in Machiavellianism could be explained by psychological sex-role variables such as normative sex-role orientations (normative behaviours for women and for men), and genderrelated self-concepts (self-perceptions of masculinity and femininity), since both the role and behaviour associated with the masculine gender are more strongly linked with Machiavellian traits (Krampen et al., 1990). On the other hand, contrary to the findings revealed by the meta-analysis conducted by Grijalva et al. (2015), gender differences were not found in total narcissism. This lack of significant differences could be due to the general increase of narcissism in current society (both for men and women; Twenge \& Campbell, 2008). Our study only showed differences in the vanity and entitlement sub-dimension of narcissism, which is in agreement with the previous

324 literature (Grijalva et al., 2015). 
In accord with Hypothesis 2, higher psychopathy and Machiavellianism scores (total score

326

327

328

329

330

331

332

333

334

335

336

337

338

339

340

341

342

343

344

345

346

347

348

349

350

351

352

353

354

and all sub-dimensions) were related to higher levels of depressive symptoms. Regarding psychopathy, there is currently an open debate concerning the relationship between this trait and depression, since some authors consider both constructs to be mutually exclusive (see Lovelace \& Gannon, 1999). This is due to the fact that psychopathy is understood as an activation disorder and, in contrast, mood dysfunctions such as depression are included among the inhibition disorders. Our findings are compatible with the results of previous studies supporting the notion that both constructs are not exclusive and that, in fact, there is a positive relationship between them (Stinson et al., 2005; Tokarev, et al., 2017). Several theories have emerged as a consequence of the need to explain these results. For example, research with adolescents has revealed that the externalization of negative moods such as anxiety or depression can result in antisocial and psychopathic behaviours (Harrington, 2001; Kasen et al., 2001; Sayar, Ebrinc, \& Ak, 2001). Another hypothesis refers to the different symptoms that define the concept of depression. Even though there are people with high psychopathic traits that do not show the emotional symptoms of depression, many of them still obtain high overall scores on this disorder since they present the physiological symptoms (Stinson et al., 2005). With respect to Machiavellianism, the positive relationship found with depression is well supported by the previous literature (e.g. Al Aïn et al. 2013). The Machiavellian concept is largely characterized by the emotional detachment that is usually observed in people who suffer from depression (Demenescu, Kortekaas, Den Boer, \& Aleman, 2010). Moreover, Machiavellianism is related to anhedonia or the inability to feel pleasure, a symptom that is frequently found in depressive disorders (Treadway \& Zald, 2011).

In relation to narcissism, the lack of a relationship between the total score of this trait and depression is in accord with Hypothesis 3 and previous findings in the literature (e.g., Jonason et al., 2015). Narcissism is a trait that differs from psychopathy and Machiavellianism in terms of its social character, where the individual tends to seek the validation of others (Raskin \& Terry, 1988). Thus, individuals with high scores on this trait often have good social support (Jonason \& Schmitt, 2012), which is considered to be a protective factor for mood disorders (Almagiá, 2014). However, although no significant results were found with total score, we found that depressive symptoms showed a negative relationship with the self-sufficiency sub-dimension, and a positive relationship with the entitlement sub-dimension. These results are unsurprising, given that self-sufficiency has

PeerJ reviewing PDF | (2019:06:38329:2:0:NEW 21 Oct 2019) 
355 previously been linked to healthier functioning, whilst entitlement has been linked to more 356 maladaptive behaviours (Watson, Grisham, Trotter, \& Biderman 1984).

357 In relation to Hypothesis 4, some of the sub-dimensions of the DT traits associated with 358 depressive symptoms showed significant differences depending on gender. The negative 359 relationship between depressive symptoms and self-sufficiency (NPI) was stronger in women than 360 men, the relationship with vanity (NPI) was only observed in women, whilst the relationship with

361

362

363

364

365

366

367

368

369

370

371

372

373

374

375

376

377

378

379

380

381

382

383

384

disregard for conventional morality (MACH-IV) was only observed in men. There are many studies that have analysed gender differences in both DT (e.g. Paulhus \& Williams 2002; Muris et al., 2017) and depression (Girgus \& Yang, 2015; Piccinelli \& Wilkinson, 2000; Salk, Petersen, Abramson, \& Hyde, 2016) separately; however, to the best of our knowledge, our study is the first to explore the moderating effect of gender on the relationship between these variables. The gender differences found in the relationship between vanity and depression could be explained by the fact that aspects of physical appearance that are included in the vanity sub-dimension are more dominant in women. In this gender, higher vanity scores are associated with greater general satisfaction with personal appearance (Grijalva et al., 2015). Thus, the result found in our study could be due to the negative relationship between body satisfaction and depressive symptoms (Rentz-Fernandes, Silveira-Viana, de-Liz, \& Andrade, 2017). Moreover, self-sufficiency in women is associated with greater economic independence and career success (Wettersten et al., 2004), which would have a strong negative association with depressive symptoms and greater life satisfaction (Montesó-Curto, 2014). Finally, in men, higher scores on disregard for conventional morality could be related to a lack of social connections, which could result in higher levels of depression, and in general, worse mental health (Jonason et al., 2015).

Particularly relevant to our aims were the findings observed in relation to Hypothesis 5. GAM analysis controlling for shared variability among the sub-dimensions of the DT traits (and gender effect) revealed that the sub-dimensions most strongly associated with depressive symptoms were callous affect (SRP-III), criminal tendencies (SRP-III), entitlement (NPI), selfsufficiency (NPI), and cynical view of human nature (MACH-IV). Thus, although previous correlation analyses showed an association between depression and a greater number of subdimensions, the effect of many of these was shared and can be explained by the sub-dimensions included in the GAM model. Working individually on each trait or sub-dimension could be 
385

386

387

388

389

390

391

392

393

394

395

396

397

398

399

400

401

402

403

404

405

406

407

408

409

410

411

412

413

414

effective, but, given the common core of characteristics shared, it makes more sense to pay particular attention to those sub-dimensions that were included in this model.

From an applied point of view, the findings of this study could have implications for the implementation of prevention and treatment programs focused on depression in individuals with high levels of DT traits. Research studying DT has usually focused on the psychological factors underlying this construct and the negative implications of these outcomes for society. However, rarely have researchers investigated the consequences that these traits may have for the individuals themselves, such as depressive symptoms. Our results suggest that the detection of high scores on certain sub-dimensions of the DT traits could be useful for informing the development of preventive interventions that would help to avoid future depressive symptoms.

Finally, it is important to address some of the limitations of this research. Although a high number of men participated in this study $(n=197)$, the sample was composed mainly of women. Future investigations should aim to use a more balanced sample. Moreover, it would be interesting to work with a clinical sample in order to replicate our results in individuals with a diagnosis of major depression based on psychiatric and clinical interviews (Sheehan et al., 1998). Finally, it must be kept in mind that the correlational analysis included in this study does not allow us to establish causal relationships. We have only focused on studying the association between both constructs. Additional prospective experimental studies would be needed to confirm the causal direction of the relationships found here.

\section{Conclusion}

The present study explored the relationship between DT traits and depressive symptoms. Our findings revealed that there are a series of factors characterising individuals with higher DT scores, which can be related to depression problems. The sub-dimensions of callous affect and criminal tendencies for psychopathy, cynical view of human nature for Machiavellianism, and entitlement and self-sufficiency for narcissism were the factors most strongly related to depressive symptoms. Furthermore, we observed how the effect of some of the DT sub-dimensions depended on gender. The results of this study could be exploited as a tool for designing prevention and intervention programs aimed at decreasing the negative consequences suffered by individuals with high DT scores. The reduction of depressive symptoms in this population can have important 
415 benefits for the individuals themselves, allowing for better integration in society and thus limiting

416 the negative consequences of these traits for the community.

417

418

419

420

421

422

423

424

425

426

427

428

429

430

431

432

433

434

435

436

437

438

439

440

441

\section{References}

Al Aïn, S., Carré, A., Fantini-Hauwel, C., Baudouin, J. Y., \& Besche-Richard, C. (2013). What is the emotional core of the multidimensional Machiavellian personality trait? Frontiers in Psychology, 4, 454. doi: 10.3389/fpsyg.2013.00454

Almagiá, E. B. (2014). Apoyo social, estrés y salud. Psicología y Salud, 14(2), 237-243. doi: $10.25009 /$ pys.v14i2.848

American Psychiatric Association. (2013). Diagnostic and statistical manual of mental disorders (DSM-5). Washington, DC: American Psychiatric Pub.

Beck, A. T., Steer, R. A., \& Brown, G. K. (1996). Beck Depression Inventory manual (2nd ed.). San Antonio, USA: Psychological Corporation.

Book, A. S., Starzyk, K. B., \& Quinsey, V. L. (2001). The relationship between testosterone and aggression: a meta-analysis. Aggression and Violent Behavior, 6(6), 579-599. doi: 10.1016/S1359-1789(00)00032-X

Cairncross, M., Veselka, L., Schermer, J. A., \& Vernon, P. A. (2013). A behavioral genetic analysis of alexithymia and the Dark Triad traits of personality. Twin Research and Human Genetics, 16(3), 690-697. doi: 10.1017/thg.2013.19

Cale, E. M., \& Lilienfeld, S. O. (2002). Sex differences in psychopathy and antisocial personality disorder: A review and integration. Clinical Psychology Review, 22(8), 1179-1207. doi: $10.1016 / \mathrm{S} 0272-7358(01) 00125-8$

Cassano, P., \& Fava, M. (2002). Depression and public health. Journal of Psychosomatic Research, 53(4), 849-857. doi: 10.1016/S0022-3999(02)00304-5

Christie, R., \& Geis, F. (1970). Studies in Machiavellianism. New York: Academic Press. 
442 Demenescu, L. R., Kortekaas, R., Den Boer, J. A., \& Aleman, A. (2010). Impaired attribution of

443

444

445

446

447

448

449

450

451

452

453

454

455

456

457

458

459

460

461

462

463

464

465

466

467

468

469 emotion to facial expressions in anxiety and major depression. PloS One, 5(12), e15058. doi: 10.1371/journal.pone.0015058

Furnham, A., Richards, S. C., \& Paulhus, D. L. (2013). The dark triad of personality: A 10 year review the dark triad of personality. Social and Personality Psychology Compass, 7(3), 199216. doi: $10.1111 / \mathrm{spc} 3.12018$

García, J. M, \& Cortés, J. F. (1998). La medición empírica del narcisismo. Psicothema, 10 (3), 725-735.

Girgus, J. S., \& Yang, K. (2015). Gender and depression. Current Opinion in Psychology, 4, 5360. doi: 0.1016/j.copsyc.2015.01.019

Gómez-Leal, R., Megías, A., Gutiérrez-Cobo, M.J., Cabello, R., Fernández-Abascal, E.G., \& Fernández-Berrocal, P. (2019). Spanish adaptation and validation of the 34-item self-report psychopathy scale (SRP). Journal of Personality Disorders, 1-19. doi: 10.1521/pedi_2019_33_434

Grijalva, E., Newman, D. A., Tay, L., Donnellan, M. B., Harms, P. D., Robins, R. W., \& Yan, T. (2015). Gender differences in narcissism: A meta-analytic review. Psychological Bulletin, 141(2), 261-310. doi: 10.1037/a0038231

Hare, R. D. (1993). Without conscience: the disturbing world of the psychopaths among us. New York: Guilford Press.

Hare, R. D., \& Neumann, C. S. (2005). Structural models of psychopathy. Current Psychiatry Reports, 7(1), 57-64. doi: 10.1007/s11920-005-0026-3

Harrington, R. C. (2001). Childhood depression and conduct disorder: different routes to the same outcome? Archives of General Psychiatry, 58(3), 237-238. doi: 10.1001/archpsyc.58.3.237

Harrop, T. M., Preston, O. C., Khazem, L. R., Anestis, M. D., Junearick, R., Green, B. A., \& Anestis, J. C. (2017). Dark traits and suicide: Associations between psychopathy, narcissism, and components of the interpersonal-psychological theory of suicide. Journal of Abnormal Psychology, 126(7), 928-938. doi: 10.1037/abn0000300

Hastie, T. J., \& Tibshirani, R. (1990). Generalized Additive Models. London: Chapman and Hall. 
470 Jonason, P. K., Baughman, H. M., Carter, G. L., \& Parker, P. (2015). Dorian Gray without his 471 portrait: Psychological, social, and physical health costs associated with the Dark Triad. Personality and Individual Differences, 78, 5-13. doi: 10.1016/j.paid.2015.01.008

473

474

475

476

477

478

479

480

481

482

483

484

485

486

487

488

489

490

491

492

493

494

495

Jonason, P. K., \& Davis, M. D. (2018). A gender role view of the Dark Triad traits. Personality and Individual Differences, 125, 102-105. doi: 10.1016/j.paid.2018.01.004

Jonason, P. K., \& Kroll, C. H. (2015). A multidimensional view of the relationship between empathy and the dark triad. Journal of Individual Differences, 36, 150-156. doi: 10.1016/j.paid.2017.11.009

Jonason, P. K., \& Schmitt, D. P. (2012). What have you done for me lately? Friendship-selection in the shadow of the Dark Triad traits. Evolutionary Psychology, 10(3), 400-421.

Jones, D. N., \& Paulhus, D. L. (2017). Duplicity among the dark triad: Three faces of deceit. Journal of Personality and Social Psychology, 113(2), 329-342. doi: $10.1037 / \mathrm{pspp} 0000139$

Kasen, S., Cohen, P., Skodol, A. E., Johnson, J. G., Smailes, E., \& Brook, J. S. (2001). Childhood depression and adult personality disorder: alternative pathways of continuity. Archives of General Psychiatry, 58(3), 231-236. doi: 10.1001/archpsyc.58.3.231

Kennealy, P. J., Skeem, J. L., Walters, G. D., \& Camp, J. (2010). Do core interpersonal and affective traits of PCL-R psychopathy interact with antisocial behavior and disinhibition to predict violence? Psychological Assessment, 22, 569-580. doi: 10.1037/a0019618

Krampen, G., Effertz, B., Jostock, U., \& Müller, B. (1990). Gender differences in personality: Biological and/or psychological? European Journal of Personality, 4, 303-317. doi: 10.1002/per.2410040404

Lépine, J. P., \& Briley, M. (2011). The increasing burden of depression. Neuropsychiatric Disease and Treatment, 7(1) 3-7. doi: 10.2147/NDT.S19617

Lovelace, L., \& Gannon, L. (1999). Psychopathy and depression: mutually exclusive constructs? Journal of Behavior Therapy and Experimental Psychiatry, 30(3), 169-176. 
496

497

498

499

500

501

502

503

504

505

506

507

508

509

510

511

512

513

514

515

516

517

518

519

520

521

522

523

524

Mahmut, M. K., Menictas, C., Stevenson, R. J., \& Homewood, J. (2011). Validating the factor structure of the Self-Report Psychopathy Scale in a community sample. Psychological Assessment, 23(3), 670-678. doi: 10.1037/a0023090

Megías, A., Gómez-Leal, R., Gutiérrez-Cobo, M. J., Cabello, R., \& Fernández-Berrocal, P. (2018). The relationship between trait psychopathy and emotional intelligence: A meta-analytic review. Neuroscience \& Biobehavioral Reviews, 84, 198-203. doi:10.1016/j.neubiorev.2017.12.00

Miao, C., Humphrey, R. H., Qian, S., \& Pollack, J. M. (2018). The Relationship between Emotional Intelligence and the Dark Triad Personality Traits: A Meta-Analytic Review. Journal of Research in Personality, 78, 189-197. doi: 10.1111/joop.12167

Miller, J. D., Dir, A., Gentile, B., Wilson, L., Pryor, L. R., \& Campbell, W. K. (2010). Searching for a Vulnerable Dark Triad: Comparing Factor 2 Psychopathy, Vulnerable Narcissism, and Borderline Personality Disorder. Journal of Personality, 78(5), 1529-1564. doi: 10.1111/j.1467-6494.2010.00660.x

Montesó-Curto, P. (2014). The construction of gender roles and their relation to chronic stress and depression in women. Revista Internacional de Trabajo Social y Ciencias Sociales, (8), 105126. doi: 10.5944/comunitania.8.6

Morf, C. C., \& Rhodewalt, F. (2001). Expanding the dynamic self-regulatory processing model of narcissism: Research directions for the future. Psychological Inquiry, 12, 243-251. doi: 10.1207/S15327965PLI1204_3

Mulder, R.T., Joyce, P.R., \& Luty, S.E. (2003). The relationship of personality disorders to treatment outcome in depressed outpatients. Journal of Clinical Psychiatry, 64, 259-64.

Muris, P., Merckelbach, H., Otgaar, H., \& Meijer, E. (2017). The malevolent side of human nature: A meta-analysis and critical review of the literature on the dark triad (narcissism, Machiavellianism, and psychopathy). Perspectives on Psychological Science, 12(2), 183204. doi: $10.1177 / 1745691616666070$

Nicholls, T. L., Ogloff, J. R., Brink, J., \& Spidel, A. (2005). Psychopathy in women: A review of its clinical usefulness for assessing risk for aggression and criminality. Behavioral Sciences \& the Law, 23(6), 779-802. doi: 10.1002/bsl.678 
525 Nock, M. K., Hwang, I., Sampson, N. A., \& Kessler, R. C. (2010). Mental disorders, comorbidity 526 and suicidal behavior: results from the National Comorbidity Survey Replication. Molecular 527 Psychiatry, 15(8), 868-876. doi: 10.1016/S0092-6566(02)00505-6

528 Paulhus, D. L. \& Williams, K. M. (2002). The dark triad of personality: Narcissism, 529 Machiavellianism, and psychopathy. Journal of Research in Personality, 36 (6): 556-563. 530 doi: 10.1016/S0092-6566(02)00505-6

531 Piccinelli, M., \& Wilkinson, G. (2000). Gender differences in depression: Critical review. The British Journal of Psychiatry, 177(6), 486-492. doi: 10.1192/bjp.177.6.486

533

534

535

536

537

538

539

540

541

542

543

544

545

546

547

548

549

550

551

552

Rada, F. M., de Lucas Taracena, M. T., \& Rodríguez, M. M. (2004). Valoración de la inteligencia maquiavélica en el trastorno antisocial mediante la Escala MACH-IV. Actas Españolas de Psiquiatría, 32, 65-70.

Ramklint, M., \& Ekselius, L. (2003). Personality traits and personality disorders in early onset versus late onset major depression. Journal of Affective Disorders, 75(1), 35-42. doi: 10.1016/S0165-0327(02)00028-9

Raskin, R., \& Hall, C. S. (1979). A narcissistic personality inventory. Psychological Reports, 45, 590-591. doi: 10.2466/pr0.1979.45.2.590

Raskin, R., \& Terry, H. (1988). A principal-components analysis of the narcissistic personality inventory and further evidence of its construct validity. Journal of Personality and Social Psychology, 54, 890-902.

Rauthmann, J. F. (2013). Investigating the MACH-IV with item response theory and proposing the trimmed MACH.Journal of personality assessment, 95(4), 388-397. doi: 10.1037/0022-3514.54.5.890

Reidy, D. E., Shirk, S. D., Sloan, C. A., \& Zeichner, A. (2009). Men who aggress against women: Effects of feminine gender role violation on physical aggression in hypermasculine men. Psychology of Men \& Masculinity, 10(1), 1-12. doi: 10.1037/a0014794

Rentz-Fernandes, A. R., Silveira-Viana, M. D., de-Liz, C. M., \& Andrade, A. (2017). Selfesteem, body image and depression in adolescents with different nutritional conditions. Revista de Salud Pública, 19(1), 111-120. 
553 Rose, P., \& Campbell, W. K. (2004). Greatness feels good: A telic model of narcissism and 554 subjective well-being. In S. P. Shohov (Ed.), Advances in Psychology Research. New York: $555 \quad$ Nova Science Publishers.

556

557

558

559

560

561

562

563

564

565

566

567

568

569

570

571

572

573

574

575

576

577

578

579

Sabouri, S., Gerber, M., Bahmani, D. S., Lemola, S., Clough, P. J., Kalak, N., Shamsi, M., Holsboer-Trachsl, E., \& Brand, S. (2016a). Examining Dark Triad traits in relation to mental toughness and physical activity in young adults. Neuropsychiatric Disease and Treatment, 12, 229-235. doi: 10.2147/NDT.S97267

Sabouri, S., Gerber, M., Lemola, S., Becker, S. P., Shamsi, M., Shakouri, Z., Bahmanie, D. S., Kalak, N., Holsboer-Trachslere, E., \& Brand, S. (2016b). Examining Dark Triad traits in relation to sleep disturbances, anxiety sensitivity and intolerance of uncertainty in young adults. Comprehensive Psychiatry, 68, 103-110. doi: 10.1016/j.comppsych.2016.03.012

Salk, R. H., Petersen, J. L., Abramson, L. Y., \& Hyde, J. S. (2016). The contemporary face of gender differences and similarities in depression throughout adolescence: development and chronicity. Journal of Affective Disorders, 205, 28-35. doi: 10.1016/j.jad.2016.03.071

Sanz, J., Perdigón, A., \& Vázquez, C. (2003). The spanish adaptation of Beck’s depression inventory-II (BDI-II): 2. Psychometric properties in the general population. Clínica $y$ Salud, 14(3), 249-280.

Sayar, K., Ebrinc, S., \& Ak, I. (2001). Alexithymia in patients with antisocial personality disorder in a military hospital setting. The Israel journal of psychiatry and related sciences, 38(2), 81-87.

Sheehan, D. V., Lecrubier, Y., Sheehan, K. H., Amorim, P., Janavs, J., Weiller, E., Hergueta, T., Baker, R., Dunbar, G. C. (1998). The Mini-International Neuropsychiatric Interview (M.I.N.I.): the development and validation of a structured diagnostic psychiatric interview for DSM-IV and ICD-10. The Journal of Clinical Psychiatry, 59(Suppl 20), 22-33.

Stalenheim, E. G., \& von Knorring, L. (1996). Psychopathy and Axis I and Axis II psychiatric disorders in a forensic psychiatric population in Sweden. Acta Psychiatrica Scandinavia, 94, 217-223. doi: 10.1111/j.1600-0447.1996.tb09852.x 
580 Stinson, J. D., Becker, J. V., \& Tromp, S. (2005). A preliminary study on findings of psychopathy 581 and affective disorders in adult sex offenders. International Journal of Law and Psychiatry, 582 28(6), 637-649. doi: 10.1016/j.ijlp.2004.10.001

583 584 585

586 587 588

Tokarev, A., Phillips, A. R., Hughes, D. J., \& Irwing, P. (2017). Leader dark traits, workplace bullying, and employee depression: Exploring mediation and the role of the dark core. Journal of Abnormal Psychology, 126(7), 911-920. doi: doi.org/10.1037/abn0000299

Treadway, M. T., \& Zald, D. H. (2011). Reconsidering anhedonia in depression: lessons from translational neuroscience. Neuroscience \& Biobehavioral Reviews, 35(3), 537-555. doi: 10.1016/j.neubiorev.2010.06.006

Twenge, J. M., \& Campbell, W. K. (2008). Increases in positive self-views among high school students: Birth-cohort changes in anticipated performance, self-satisfaction, self-liking, and self-competence. Psychological Science, 19(11), 1082-1086. doi: 10.1111/j.14679280.2008.02204.x

Vitacco, M. J., Neumann, C. S., \& Jackson, R. L. (2005). Testing a four-factor model of psychopathy and its association with ethnicity, gender, intelligence, aviolence. Journal of Consulting and Clinical Psychology, 73(3), 466-476. doi: 10.1037/0022-006X.73.3.466

Watson, P. J., Grisham, S. O., Trotter, M. V., \& Biderman, M. D. (1984). Narcissism and empathy: Validity evidence for the Narcissistic Personality Inventory. Journal of Personality Assessment, 48(3), 301-305. doi: 10.1207/s15327752jpa4803_12

Watts, A. L., Waldman, I. D., Smith, S. F., Poore, H. E., \& Lilienfeld, S. O. (2017). The nature and correlates of the dark triad: The answers depend on the questions. Journal of Abnormal Psychology, 126 (7), 951-968. doi: 10.1037/abn0000296

Wettersten, K. B., Rudolph, S. E., Faul, K., Gallagher, K., Trangsrud, H. B., Adams, K., Graham, S. \& Terrance, C. (2004). Freedom Through Self-Sufficiency: A Qualitative Examination of the Impact of Domestic Violence on the Working Lives of Women in Shelter. Journal of Counseling Psychology, 51(4), 447-462. doi: 10.1037/0022-0167.51.4.447

Wood, S. N. (2017). Generalized additive models: an introduction with R. New York: Chapman and Hall/CRC. 
608 World Medical Association. (2008). World Medical Association Declaration of Helsinki: ethical 609 principles for medical research involving human subjects. Retrieved from 610 https://www.wma.net/what-we-do/medical-ethics/declaration-of-helsinki/

611 Figure captions.

612 Figure 1. Plots showing the smooth components of the fitted GAM. The solid black line denotes 613 the relationship between significant DT sub-dimensions and depressive symptoms estimated from 614 the GAM. The grey shaded area indicates $95 \%$ confidence intervals. The estimated degrees of 615 freedom of the smooth curves are shown in parentheses on y-axis. Panel A: callous affect (CA); 616 panel B: criminal tendencies (CT); panel C: self-sufficiency (SS); panel D: entitlement (ENT); 617 panel E: cynical view of human nature (V). 


\section{Figure 1}

Plots showing the smooth components of the fitted GAM.

The solid black line denotes the relationship between significant DT sub-dimensions and depressive symptoms estimated from the GAM. The grey shaded area indicates $95 \%$ confidence intervals. The estimated degrees of freedom of the smooth curves are shown in parentheses on $\mathrm{y}$-axis. Panel A: callous affect (CA); panel B: criminal tendencies (CT); panel C: self-sufficiency (SS); panel D: entitlement (ENT); panel E: cynical view of human nature (V). 
A)

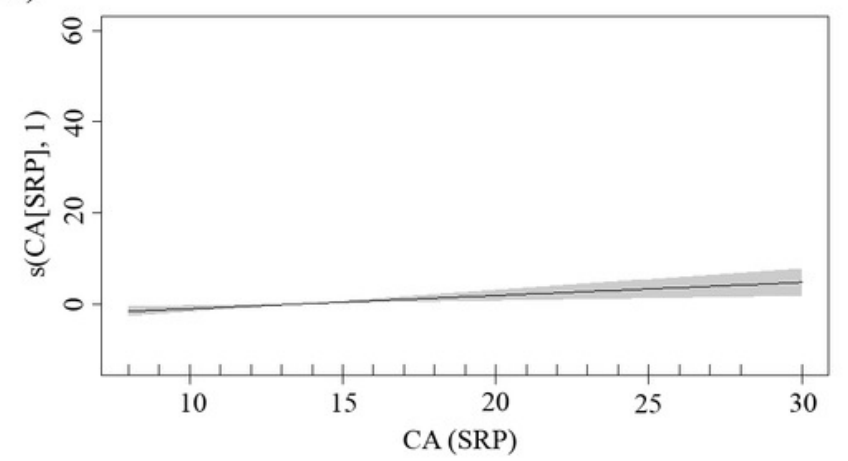

C)

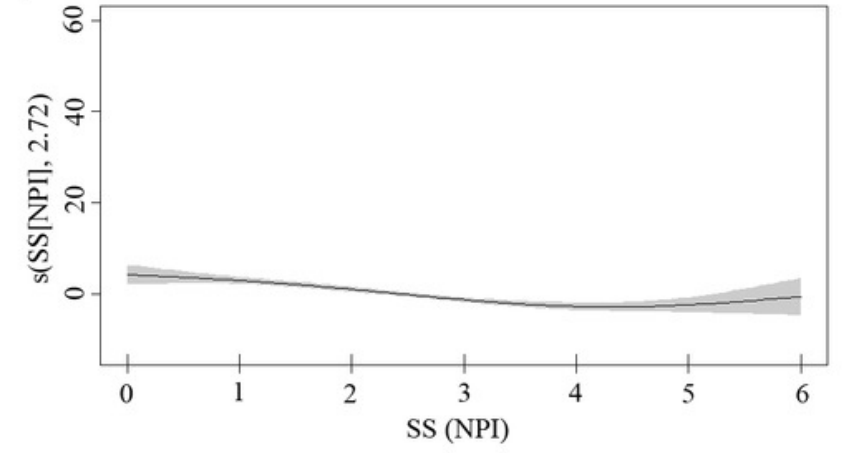

B)

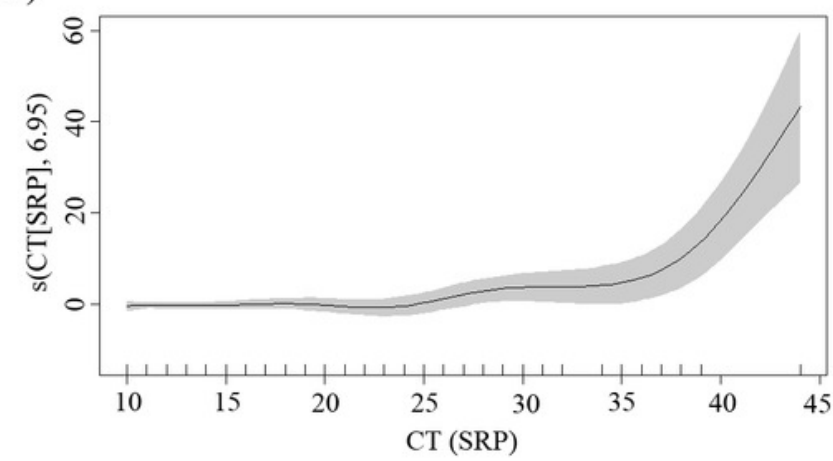

D)

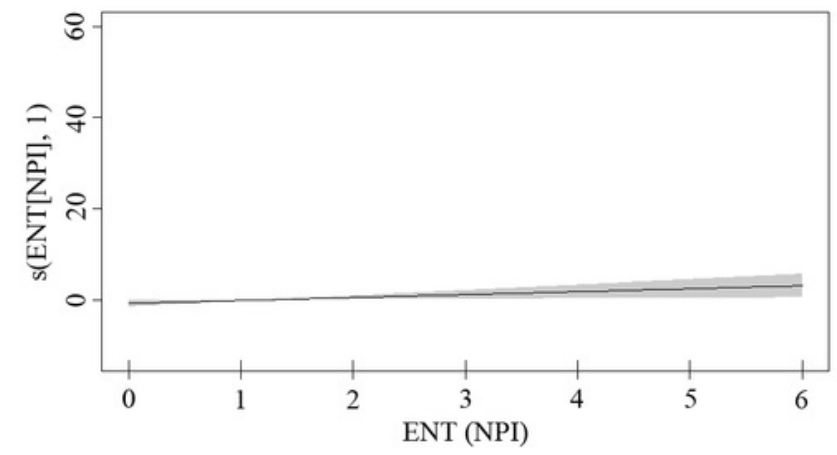

E)

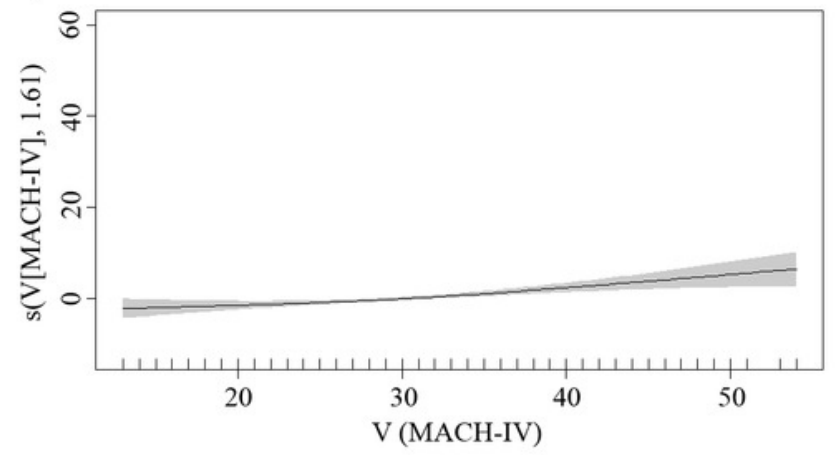




\section{Table $\mathbf{1}$ (on next page)}

Table 1. Means, standard deviations (SD), and Mann-Whitney U test with effect size (r) for gender differences. 
Table 1. Means, standard deviations (SD), and Mann-Whitney U test with effect size (r) for gender 2 differences.

\begin{tabular}{|c|c|c|c|c|c|c|c|c|}
\hline & \multicolumn{2}{|c|}{ Global Sample } & \multicolumn{2}{|c|}{ Men } & \multicolumn{2}{|c|}{ Women } & \multirow[b]{2}{*}{$\begin{array}{c}\text { Mann-Whitney } \\
\text { U }\end{array}$} & \multirow[b]{2}{*}{$\begin{array}{l}\text { Effect } \\
\text { size (r) }\end{array}$} \\
\hline & Mean & SD & Mean & SD & Mean & SD & & \\
\hline BDI Total & 8.42 & 8.57 & 7.48 & 7.80 & 8.73 & 8.80 & 54537 & 0.05 \\
\hline SRP-III Total & 61.04 & 14.06 & 66.18 & 16.26 & 59.34 & 12.82 & $42988 * *$ & 0.20 \\
\hline MACH-IV & 67.10 & 13.61 & 69.01 & 14.81 & 66.47 & 13.15 & $52739 *$ & 0.07 \\
\hline NPI Total & 11.96 & 5.05 & 12.39 & 5.30 & 11.82 & 4.96 & 54869 & 0.04 \\
\hline IPM (SRP-III) & 14.76 & 4.68 & 16.47 & 5.18 & 14.19 & 4.35 & $41895 * *$ & 0.21 \\
\hline CT (SRP-III) & 15.31 & 5.55 & 17.27 & 6.56 & 14.66 & 5.01 & $43674 * *$ & 0.19 \\
\hline ELS (SRP-III) & 17.37 & 5.36 & 18.39 & 5.82 & 17.03 & 5.16 & $50516^{* *}$ & 0.10 \\
\hline CA (SRP-III) & 13.61 & 3.32 & 14.05 & 3.52 & 13.46 & 3.24 & 53229 & 0.07 \\
\hline T (MACH-IV) & 28.05 & 7.39 & 29.26 & 7.88 & 27.65 & 7.18 & $51335 * *$ & 0.09 \\
\hline V (MACH-IV) & 29.31 & 7.10 & 29.95 & 7.29 & 29.10 & 7.02 & 54665 & 0.05 \\
\hline M (MACH-IV) & 1.51 & 0.91 & 1.67 & 1.07 & 1.46 & 0.84 & $52679^{*}$ & 0.09 \\
\hline AUT (NPI) & 3.08 & 1.47 & 3.19 & 1.53 & 3.04 & 1.45 & 54846 & 0.05 \\
\hline SS (NPI) & 2.54 & 1.25 & 2.58 & 1.19 & 2.53 & 1.27 & 56593 & 0.03 \\
\hline VAN (NPI) & 0.80 & 0.93 & 0.66 & 0.92 & 0.84 & 0.93 & $51280 * *$ & 0.10 \\
\hline EXP (NPI) & 1.40 & 1.24 & 1.51 & 1.26 & 1.36 & 1.24 & 54391 & 0.05 \\
\hline ENT (NPI) & 1.24 & 1.06 & 1.43 & 1.14 & 1.18 & 1.02 & $51525 * *$ & 0.09 \\
\hline SUP (NPI) & 1.61 & 1.07 & 1.75 & 1.16 & 1.56 & 1.03 & 53441 & 0.07 \\
\hline EXH (NPI) & 1.30 & 1.48 & 1.26 & 1.51 & 1.32 & 1.47 & 56280 & 0.03 \\
\hline
\end{tabular}

Note: SRP-III (IPM: interpersonal manipulation, CT: criminal tendencies, ELS: erratic lifestyle, CA: callous affect); MACH-IV (T: interpersonal tactics, V: cynical view of human nature, M: Disregard for conventional morality); NPI (AUT: authority, SS: self-sufficiency, VAN: vanity, EXP: exploitativeness, ENT: entitlement, SUP: superiority, EXH: exhibitionism).

$* p<.05, * * p<.01$ 


\section{Table 2 (on next page)}

Table 2. Spearman's correlations between (sub)dimensions of DT and depression. 
1 Table 2. Spearman's correlations between (sub)dimensions of DT and depression.

\begin{tabular}{|c|c|c|c|c|c|c|c|c|c|c|c|c|c|c|c|c|c|}
\hline & $\begin{array}{l}\text { SRP- } \\
\text { III } \\
\text { Total }\end{array}$ & $\begin{array}{l}\text { MACH- } \\
\text { IV Total }\end{array}$ & $\begin{array}{l}\text { NPI } \\
\text { Total }\end{array}$ & $\begin{array}{c}\text { IMP } \\
\text { (SRP- } \\
\text { III) }\end{array}$ & $\begin{array}{c}\text { CT } \\
\text { (SRP- } \\
\text { III) }\end{array}$ & $\begin{array}{c}\text { ELS } \\
\text { (SRP- } \\
\text { III) }\end{array}$ & $\begin{array}{c}\text { CA } \\
\text { (SRP- } \\
\text { III) }\end{array}$ & $\begin{array}{c}\text { T } \\
\text { (MACH } \\
\text {-IV) }\end{array}$ & $\begin{array}{c}\mathrm{V} \\
\text { (MACH } \\
\text {-IV) }\end{array}$ & $\begin{array}{c}\mathrm{M} \\
\text { (MACH } \\
-\mathrm{IV})\end{array}$ & $\begin{array}{l}\text { AUT } \\
\text { (NPI) }\end{array}$ & $\begin{array}{c}\text { SS } \\
\text { (NPI) }\end{array}$ & $\begin{array}{l}\text { VAN } \\
\text { (NPI) }\end{array}$ & $\begin{array}{l}\text { EXP } \\
\text { (NPI) }\end{array}$ & $\begin{array}{l}\text { SUP } \\
\text { (NPI) }\end{array}$ & $\begin{array}{l}\text { EXH } \\
\text { (NPI) }\end{array}$ & $\begin{array}{l}\text { ENT } \\
\text { (NPI) }\end{array}$ \\
\hline Whole sample & $.27 * *$ & $.30 * *$ & -.03 & $.20^{* *}$ & $.20^{* *}$ & $.14^{* *}$ & $.29 * *$ & $.24 * *$ & $.30 * *$ & $.09 *$ & .02 & $-.28 * *$ & -.07 & -.01 & -.05 & .06 & $.14 * *$ \\
\hline Men & $.32 * *$ & $.38^{* *}$ & .10 & $.23^{* *}$ & $.30^{* *}$ & $.15^{*}$ & $.25^{* *}$ & $.30 * *$ & $.34 * *$ & $.22 * *$ & .02 & $-.16^{*}$ & .07 & .09 & .05 & $.15^{*}$ & $.20 * *$ \\
\hline Women & $.28 * *$ & $.29^{* *}$ & -.07 & $.22^{* *}$ & $.20^{* *}$ & $.14^{* *}$ & $.32 * *$ & $.23 * *$ & $.29 * *$ & .05 & .03 & $-.32 * *$ & $-.12 * *$ & -.03 & $-.08 *$ & .04 & $.13^{* *}$ \\
\hline
\end{tabular}

Note: SRP-III (IPM: interpersonal manipulation, CT: criminal tendencies, ELS: erratic lifestyle, CA: callous affect); MACH-IV (T: interpersonal tactics, V: cynical view of human nature, M: disregard for conventional morality); NPI (AUT: authority, SS: self-sufficiency, VAN: vanity, EXP: exploitativeness, ENT: entitlement, SUP: superiority, EXH: exhibitionism).

$* p<.05, * * p<.01$ 